\title{
Decomposition of benzene by non-thermal plasma processing: Photocatalyst and ozone effect
}

\author{
${ }^{1^{*}}$ T. Zhu; ${ }^{1}$ J. Li; ${ }^{1}$ Y. Jin; ${ }^{2}$ Y. Liang; ${ }^{2}$ G. Ma \\ ${ }^{1}$ College of Environmental and Energy Engineering, Beijing University of Technology, Beijing 100022, China \\ ${ }^{2}$ Department of Environmental Engineering, Xi'an University of Architecture and Technology, Xi'an 710055, China
}

Received 5 January 2008; $\quad$ revised 8 February 2008; accepted 29 March 2008; available online 1 June 2008

\begin{abstract}
Plasma technology has some shortcomings, such as higher energy consumption and byproducts produced in the reaction process. However non-thermal plasma associated with catalyst can resolve these problems. Therefore this kind of technology was paied more and more attention to treat waste gas. A hybrid system comprising a non-thermal plasma reactor and nanometer titanium dioxide catalyst was used for benzene removal in the air. The paper described the synergistic effect of ozone and photocatalyst in the plasma reactor. Except of electric field strength, humidity and flow velocity, the synergistic behavior of ozone and photocatalyst was tested. The removal efficiency of benzene reaches nearly $99 \%$ when benzene concentration is $600 \mathrm{mg} / \mathrm{m}^{3}$, and the removal efficiency of benzene also reaches above $90 \%$ when benzene concentration is $1500 \mathrm{mg} / \mathrm{m}^{3}$. The plasma reactor packed with photocatalyst shows a better selectivity of carbon dioxide than that without photocatalyst. The final products is mostly carbon dioxide, water and a small quantity of carbon monoxide.
\end{abstract}

Key words: Synergistic effect, removal efficiency, non-thermal plasma, selectivity of carbon dioxide

\section{INTRODUCTION}

Volatile organic compounds (VOCs) are triggering serious environmental problems such as stratospheric ozone depletion and photochemical smog. Although benzene is an important chemical feedstock and additive, it should be removed from exhaust gases emitted from various moving and stationary sources due to its carcinogenicities and respiratory disorders(Noel, 2000). The traditional methods of VOCs removal such as absorption, adsorption, and incineration and so on, which were referred to the new environmental condition had many technical and economical disadvantages (Ma, 2003). In these years, some new technologies, such as biologic process, photocatalysis process, and plasma technology, were paid more and more attention (Ogata, 1999; Futamura et al., 2004; Li et al., 1998; Magureanu, 2007; Urashima et al., 2000; Zhu et al., 2007a). In particular, non-thermal plasma has attracted much attention as an method for VOCs control for two decades due to its unique properties such as quick response at ambient temperature, achievement of high electron energies within short residence times, system compactness, and easy operations (Muhamad, 2000; Li et al., 2006). In

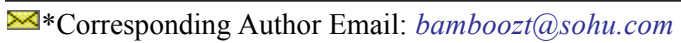

Tel.: +8610673920 80; Fax: +861067392080 order to improve the energy efficiency of the VOCs decomposition process by the plasma, the cooperation with catalyst has been tested by some researchers (Einaga et al., 2001; Guo et al., 2006; Jim, 2008; Krawczyk, 2001; Magureanu et al., 2007a and b; Ogata et al., 2003; Wallis et al., 2007; Li et al., 2007; Zhu et al., 2007b). These studies showed that the combination of discharge plasma with catalyst is a very effective method in VOCs removal. (Wallis, 2007; Durme et al., 2007; Magureanu, 2005; Delagrange et al., 2007; Guo et al., 2007). In this paper, the combination of nonthermal plasma was tried with nanometer titanium dioxide $\left(\mathrm{TiO}_{2}\right)$ photocatalyst for benzene removal, in order to further reduced the energy consumption and harmful byproducts in plasma process. Discharge plasma as a driving force of photocatalyst furnished a mess of UV light. Hole-electron pairs are produced by supplying energy larger than the band-gap energy of $\mathrm{TiO}_{2}(3.2 \mathrm{eV}$ for Anatase type). High-energy particles, such as electrons, excited molecules, and radicals may transfer their energy to $\mathrm{TiO}_{2}$ by bombardment when $\mathrm{TiO}_{2}$ is placed in a nonthermal plasma (Thevenet et al., 2007; Yoichi et al., 2008).Various chemical reactions are induced on the excited $\mathrm{TiO}_{2}$ surface through the following reactions: 
$\mathrm{TiO}_{2}+$ Plasma $\rightarrow h^{+}+e^{-}$

$h^{+}+\mathrm{H}_{2} \mathrm{O} \rightarrow \mathrm{OH}+\mathrm{H}^{+}$

$e^{-}+\mathrm{O}_{2} \rightarrow \mathrm{O}_{2}^{-}$

$e^{-}+\mathrm{H}_{2} \mathrm{O}_{2} \rightarrow \mathrm{OH}+\mathrm{OH}^{-}$

$\mathrm{O}_{2}^{-}+\mathrm{H}^{+} \rightarrow \mathrm{HO}_{2}$

Radicals + Reactant $\longrightarrow$ Products

This paper illuminates the experimental results of the synergistic effect of non-thermal plasma generated by dielectric barrier discharge (DBD) and $\mathrm{TiO}_{2}$ photocatalyst on benzene decomposition.

\section{MATERIALS AND METHODS}

The reaction system was a tube-wire packed-bed reaction system at atmospheric pressure. The schematic diagram of the testing apparatus is shown in Fig. 1. To clarify the destruction process, dry air $\left(78 \% \mathrm{~N}_{2}, 21 \%\right.$ $\mathrm{O}_{2}$ ) was used as a balance gas for benzene. Air supplied from the laboratory was divided into two air flows. Each flow rate was controlled with a flow meter. One air flow was introduced into 3 (VOCs bottle) which contained liquid VOCs. The air with almost saturated vapor of VOCs was mixed with the other air flow into 4 (blender) and diluted to the prescribed concentration of VOCs. A packed reactor with coaxial electrodes was designed as shown in Figs. 1 to 7. The reactor was made of 50 $\mathrm{mm}$ diameter ceramic tube, with an effective reactor length of $500 \mathrm{~mm}$. One electrode $(1.5 \mathrm{~mm})$ was inside and the other electrode was wrapped around the outside and grounded (80 circles). For increasing discharge, the packed materials (Rasching ring) were packed between the two electrodes. The packed materials ( $5 \mathrm{~mm}$ i.d., $1 \mathrm{~mm}$ wall thick, $10 \mathrm{~mm}$ length) which were electrician ceramic rings, were divided into two groups, coated with photocatalyst or without photocatalyst. The characteristic of packed materials includes volume density is $217 \mathrm{~g} / \mathrm{cm}^{3}$, hole rate is $12.7 \%$ and bibulous is $5.9 \%$. Nano- $\mathrm{TiO}_{2}$ thin films were prepared by the Sol-Gel method (Li et al., 1996; Liang et al., 2006) in the experiment.

\section{Precursor solution}

1 mol Tetrabutyl Titanate (Precursor Substance) + $12 \mathrm{~mol}$ Ethanol (Solvent) + $1.2 \mathrm{~mol}$ Acetyiacetone (Chelating Reagent)

\section{Droplet solution}

6 mol Ethanol (Solvent) $+1 \mathrm{~mol} \mathrm{HNO}_{3}($ Catalyzer $)+$ 2.5 mol Distilled Water

Droplet solution was dropped slowly into original solution at 35 and the whole solution was mixed well together. The steady Sol would be obtained and then the Sol should be deposited at least $24 \mathrm{~h}$. The packed materials must be washed by ultrasonic before they were immerged into the Sol. Later, they were pulled out from the Sol at the speed of $1.5 \mathrm{~mm} / \mathrm{s}$ to get the nanometer $\mathrm{TiO}_{2}$ film. The packed materials with nanometer film would be dryed at $80^{\circ} \mathrm{C}$ for one hour before they were put into muffle to calcine at $450{ }^{\circ} \mathrm{C}$ for $2 \mathrm{~h}$. At last, the film gradually refrigerated to ambient temperature.

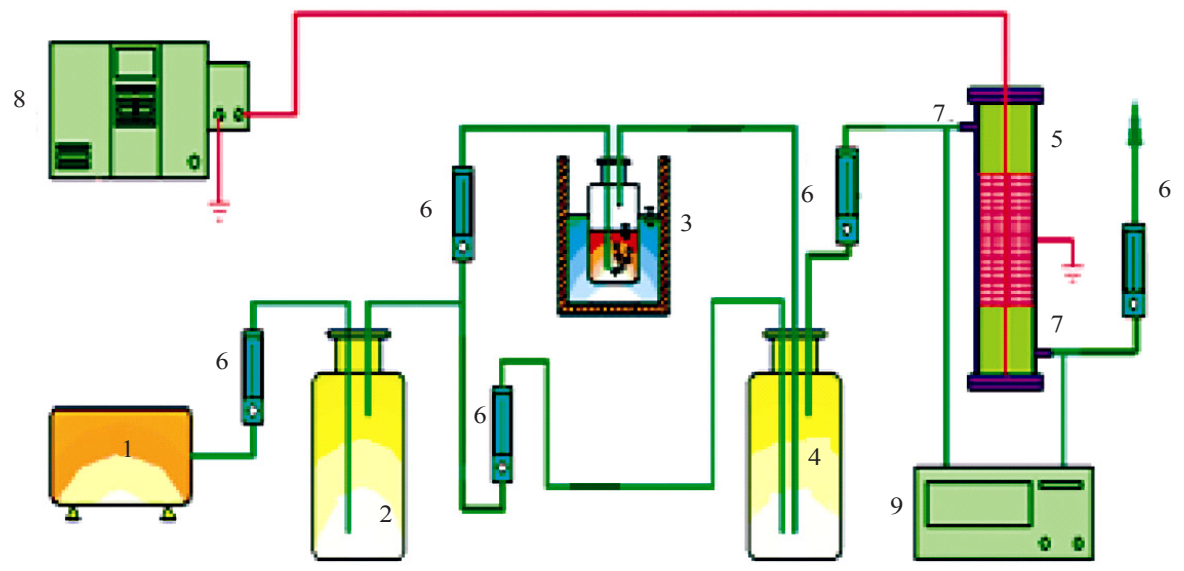

Fig. 1: The flowchart od benzene removal 1. pump 2. buffer 3.VOCs bottle 4.blender 5. reactor 6. flowmeter 7. sampling port 8 . high voltage $9 . \mathrm{GC}$ 


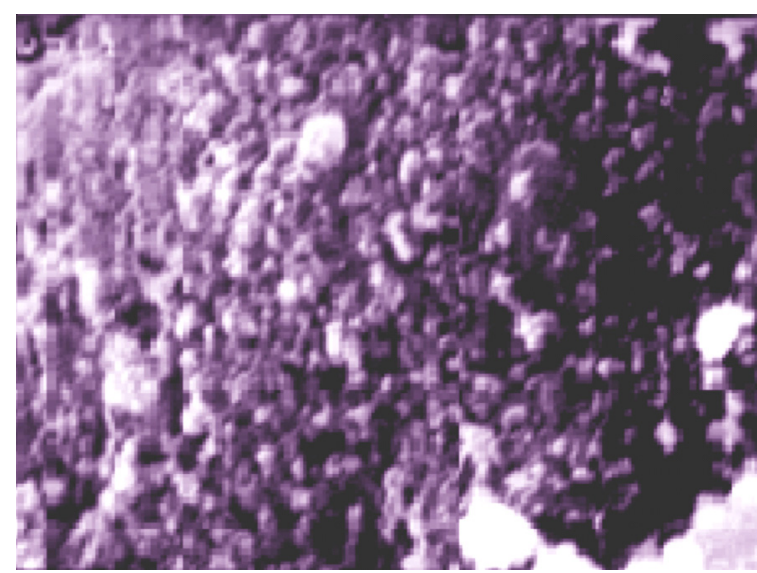

Fig. 2: SEM micrograph of the sample

The nanometer $\mathrm{TiO}_{2}$ thin film was inspected and analyzed by Scan Electric Mirror (SEM, Made in Japan, S-2700). Fig. 2 shows SEM photograph for surface situation of the samples. The average particulate diameters of $\mathrm{TiO}_{2}$ were less than $100 \mathrm{~nm}$ by SEM. Therefore $\mathrm{TiO}_{2}$ samples made by self were of nanometer levels. The conjugate chemical bonds of benzene $\left(\mathrm{C}_{6} \mathrm{H}_{6}\right)$ locate the same plane. Due to benzene possessing syntony stability, this kind of chemical bonds is more fastness and steady than common chemical bonds. So benzene was chose as a kind of VOCs to decompose in the experiment because of its stabilization of chemical structure. The plasma reactor employed an AC power supply of $60 \mathrm{~Hz}$. The AC voltage was applied to the reactor in the radial direction, and the voltage extension changed from $10 \mathrm{kV}$ to $30 \mathrm{kV}$. Chromatographic analysis and calculation were carried out by gas chromatography (manufactured by American Thermo Finnigan Co., TRACE-GC ULTRA) with a flame ionization detector (FID). Separately, another GC (SC1001) equipped with an FID detector and an methane converter was used to analyze concentration of $\mathrm{CO}_{2}$ and $\mathrm{CO}$. Reaction gas samples were taken by a syringe from the sampling ports of the reactor. The concentration of ozone $\left(\mathrm{O}_{3}\right)$ was measured by iodinetitration and the byproducts were identified by GC-MS with a 30-m-long wide-bore capillary column (DB-1). The experimental condition was in atmospheric pressure $(760 \mathrm{mmHg})$ and temperature $\left(20^{\circ} \mathrm{C}\right)$.

\section{RESULTS AND DISCUSSION}

Fig. 3 shows the relationship between removal efficiency of benzene and electrostatic field strength in the plasma reactor with or without packed materials.

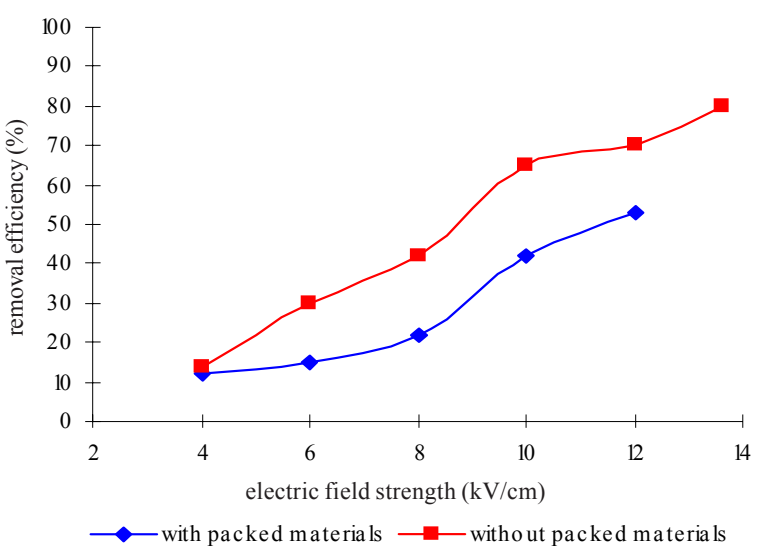

Fig. 3: The effect of removal efficiency with or without packed materials

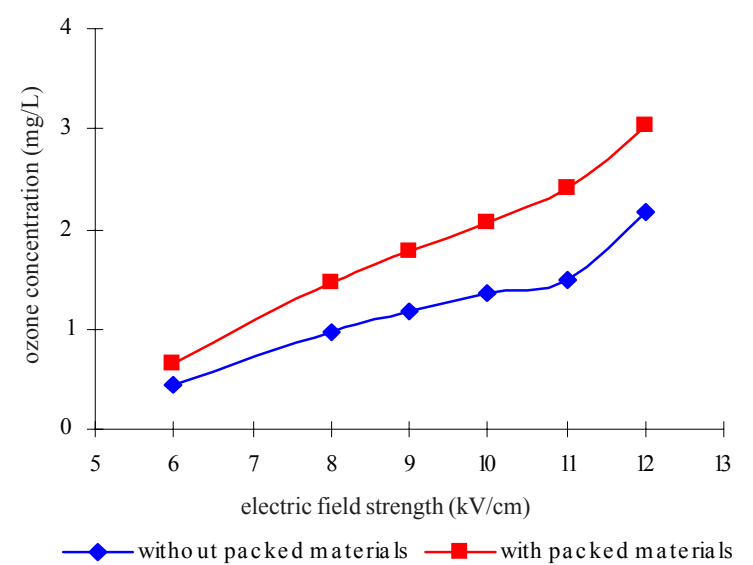

Fig. 4: The effect of ozone concentration with or without packed materials

Fig. 4 shows the relationship between ozone concentration and electrostatic field strength in the plasma reactor with or without packed materials. With increasing electrostatic field strength, the removal efficiency of benzene increases. When initial concentration of benzene is $1300 \mathrm{mg} / \mathrm{m}^{3}$, the average electrostatic field strength is $13.6 \mathrm{kV} / \mathrm{cm}$ and gas flux is $100 \mathrm{~L} / \mathrm{h}$., the removal efficiency of benzene arrives at $80 \%$ in the reactor with packed materials as shown in Fig. 3. In the reactor, the space occupied by contamination air is always full of high energy electrons (Yang, 1983). When effective collisions between high energy electrons and benzene molecules take place in the reactor, electron energy will destruct molecular structure of benzene and benzene molecules will be 
converted into inorganic little molecules like carbon dioxide $\left(\mathrm{CO}_{2}\right)$, carbon monoxide $(\mathrm{CO})$ and water $\left(\mathrm{H}_{2} \mathrm{O}\right)$. Thus, removal efficiency of benzene are proportional to the electrons. In Fig. 3, when packed materials placed in the plasma reactor, with electrostatic field strength increasing, more and more high energy electrons are produced due to mediums polarization of packed materials. So packed materials in the reactor increases the removal efficiency of benzene. Fig. 4 shows when initial concentration of benzene is $1300 \mathrm{mg} / \mathrm{m}^{3}$, the average electrostatic field strength is $12 \mathrm{kV} / \mathrm{cm}$ and gas flux is $100 \mathrm{~L} / \mathrm{h}$., ozone concentration is about 3.04 $\mathrm{mg} / \mathrm{L}$ with packed materials and ozone concentration is about $2.16 \mathrm{mg} / \mathrm{L}$ without packed materials. Ozone concentration with packed materials heightens $1 \mathrm{mg} / \mathrm{L}$ than that without packed materials in the plasma reactor. It is obvious that packed materials in the reactor is helpful of increasing ozone concentration. The reason is high energy electrons and radicals are generated in the early discharge phase. They possess high energy compared to the dissociation energy of $\mathrm{O}_{2}$ so that a series of reaction takes place in the plasma. The oxygen dissociation is the most important radical formation reaction.

$$
e+\mathrm{O}_{2} \rightarrow e+\mathrm{O}+\mathrm{O}
$$

Electronically excited atomic oxygen $\left(\mathrm{O}\left({ }^{1} \mathrm{D}\right)\right)$ are very short-lived radicals, whereas ground state atomic oxygen $(\mathrm{O})$ and hydroxyl $(\mathrm{OH})$ have a longer lifetime. $\mathrm{O}\left({ }^{1} \mathrm{D}\right)$ reacts with $\mathrm{H}_{2} \mathrm{O}$ resulting in formation of $\mathrm{OH}$ radicals. $\mathrm{O}^{-}$and $\mathrm{OH}^{-}$radicals are removed by formation of $\mathrm{O}_{3}$. In Figs. 3 and 4, the test results also indicate ozone is helpful for benzene removal, at least, ozone acts as the oxidant precursor. With ozone concentration increasing, the removal efficiency of benzene increases. Because ozone as a kind of oxidative species produced by the initial oxidation just like $\mathrm{OH}$ radical, has an effect on further reaction of benzene. The humidities of contaminated air in the reactor have influence on ozone concentration as shown in Fig. 5a. Ozone concentration without vapor is higher $35 \%$ than that with relative humidity $67 \%$, and ozone concentration decreases with humidity increasing. Because $\mathrm{H}_{2} \mathrm{O}$ molecule have electronegative, it will consume the electrons in the plasma. At the same time, $\mathrm{H}_{2} \mathrm{O}$ will react with $\mathrm{O}\left({ }^{1} \mathrm{D}\right)$ which is the origin of formation of $\mathrm{O}_{3}$.

$\mathrm{H}_{2} \mathrm{O}+\mathrm{O}\left({ }^{1} \mathrm{D}\right) \rightarrow 2 \mathrm{OH}$
So humidity counteracts the formation of ozone.

In Fig. 5b, the findings show the removal efficiency reduces with humidity increasing. Probably, the active sites for benzene removal are reduced by water vapor occurring competitive adsorption on the surface of nano- $\mathrm{TiO}_{2}$. Thus, humidity affects the benzene removal in three ways: deactivation of high energy electrons, inhibition of ozone formation, and suppression of the catalyst activity of nano- $\mathrm{TiO}_{2}$ for benzene oxidation with ozone in the plasma reactor. Fig. 6 shows the relationship between ozone concentration and gas flux with catalyst or without catalyst in the plasma reactor under three initial concentration of benzene. When gas passes the reactor, and electrostatic field strength is

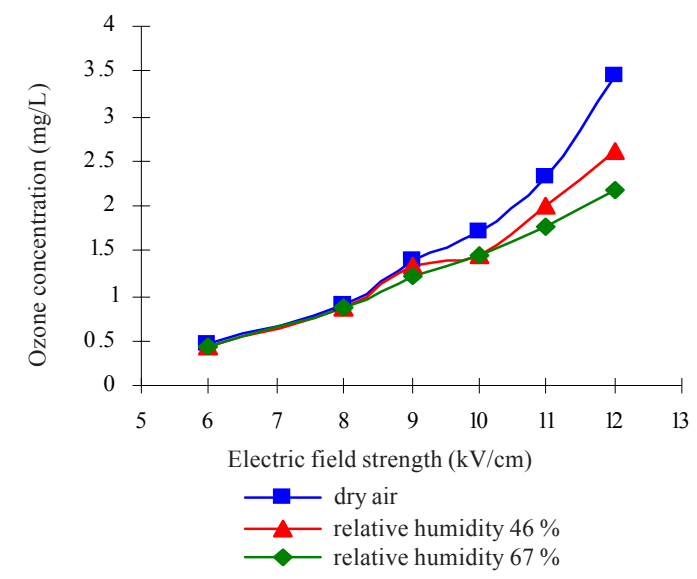

Fig. 5a: The effect of humidity on ozone concentration without photocatalyst

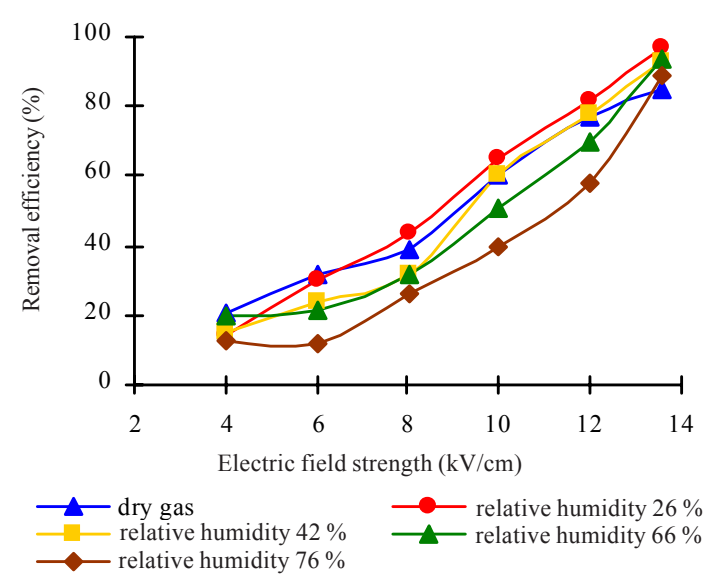

Fig. 5b: The effect of humidity on removal efficiency with photocatalyst 


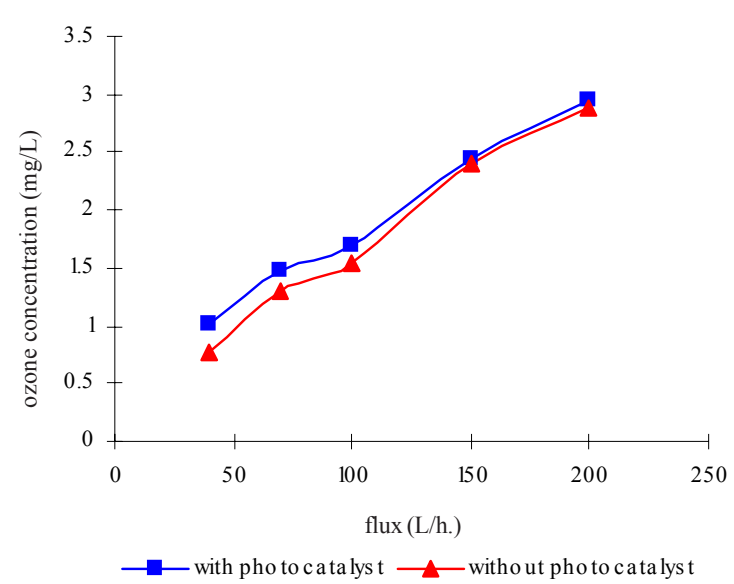

Fig. 6a: Relationship between ozone concentration and flux with or without catalyst when benzene concentration is $0 \mathrm{mg} / \mathrm{m}^{3}$

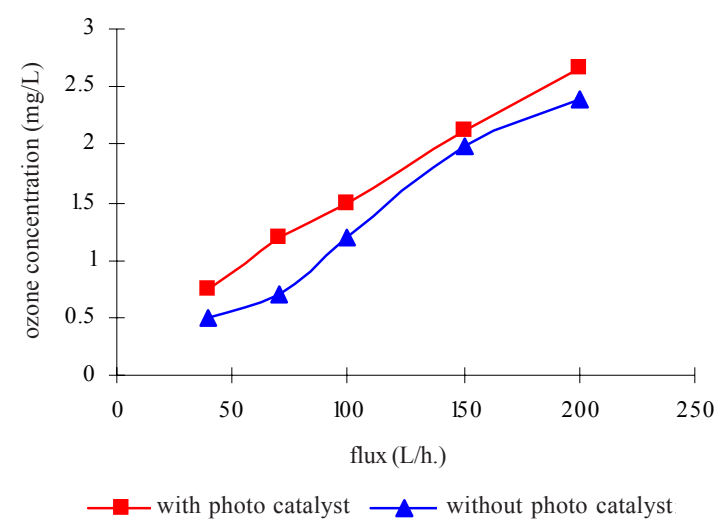

Fig. 6c: Relationship between ozone concentration and flux with or without catalyst when benzene concentration is $2000 \mathrm{mg} / \mathrm{m}^{3}$

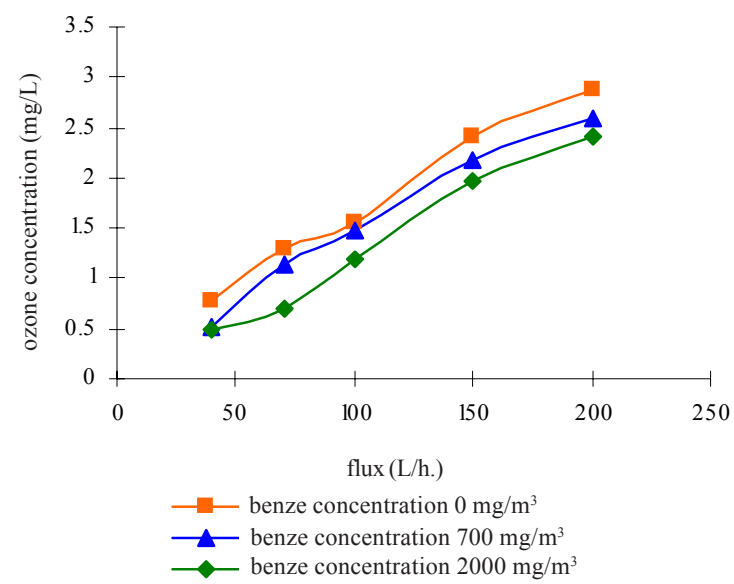

Fig. 6e: Relationship between ozone concentration and flux without catalyst

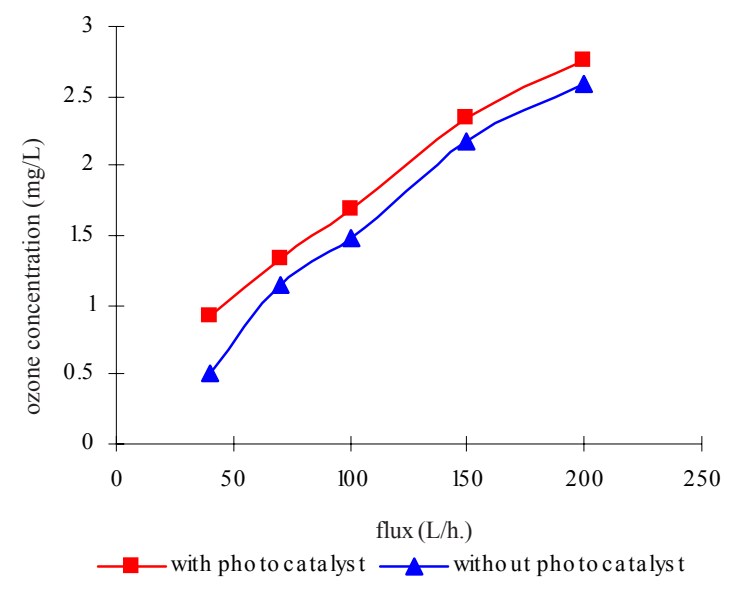

Fig. 6b: Relationship between ozone concentration and flux with or without catalyst when benzene concentration is $700 \mathrm{mg} / \mathrm{m}^{3}$

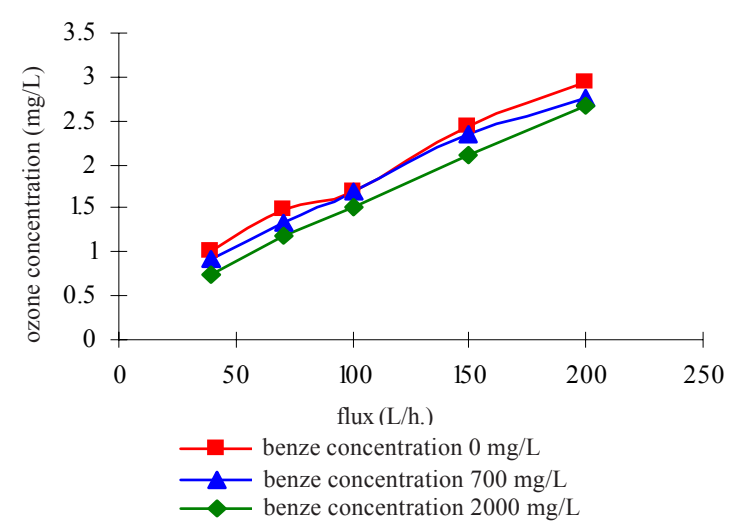

Fig. 6d: Relationship between ozone concentration and flux with catalyst

$10 \mathrm{kV} / \mathrm{cm}$, ozone concentration increases with gas flux increasing as shown in Figs. 6a, b and c, regardless of with or without photocatalyst. Fig. $6 \mathrm{~d}$ and $6 \mathrm{e}$ show benzene concentration reduces with initial concentration of benzene increasing, regardless of with or without photocatalyst.

The relationship between benzene degradation and electrostatic field strength with or without photocatalyst is shown in Fig. 7 where benzene initial concentrations changes from $600 \mathrm{mg} / \mathrm{m}^{3}$ to $1500 \mathrm{mg} /$ $\mathrm{m}^{3}$. When initial concentration is $600 \mathrm{mg} / \mathrm{m}^{3}$, the average electrostatic field strength is $10 \mathrm{kV} / \mathrm{cm}$, and gas flow rate is $14 \mathrm{~mm} / \mathrm{s}$, the removal efficiency of benzene attains $98 \%$ in the reactor with photocatalyst, but the removal efficiency of benzene attains $78 \%$ in the reactor without photocatalyst as shown in Fig. 7a. When initial 
concentration is $1500 \mathrm{mg} / \mathrm{m}^{3}$, the average electrostatic field strength is $12 \mathrm{kV} / \mathrm{cm}$ and gas flow rate is $14 \mathrm{~mm} / \mathrm{s}$, the removal efficiency is higher $19 \%$ with photocatalyst than without photocatalyst in the plasma reactor as shown in Fig. 7b. The results indicate photocatalyst enhanced the benzene removal efficiency obviously with ozone. When both photocatalyst and ozone coexist, there will be an improved removal efficiency of benzene in the plasma reactor. $\mathrm{TiO}_{2}$ is a photocatalyst material of $3.2 \mathrm{eV}$ band gap. Which if it absorbs bigger energy than band gap, it makes photo-excited electronhole pairs that could oxidize benzene. At same time, the surface hydroxyl groups are oxidized to form composition of benzene in the photocatalytic reactions. Therefore it was advantageous to use photocatalyst in plasma system to control of oxidation step of benzene.

The influence of the catalyst on ozone formation is presented in Figs. 6a, b and c. It shows the catalyst could reduce the ozone formation to a certain extent. This is because ozone as the main long-living radical can capture free electrons which are produced by photocatalysis and produce $\mathrm{OH}$ radical. It avoids not only hole-electron pairs compounding but also increases photons efficiency. Further more, $\mathrm{OH}$ radical is a kind of good oxidant and it can transform organism into mineral. (Zhang et al., 2003; Maria et al., 2002).

$\mathrm{O}_{3}+e^{-} \rightarrow \mathrm{O}_{3}^{-}$

$\mathrm{H}^{+}+\mathrm{O}_{3}^{-} \bullet \mathrm{HO}_{3} \bullet$

$\mathrm{HO}_{3} \bullet \rightarrow \mathrm{O}_{2}+\bullet \mathrm{OH}$

$\mathrm{O}_{3}+h v \rightarrow \bullet O+\mathrm{O}_{2}$

- $\mathrm{O}+\mathrm{H}_{2} \mathrm{O} \rightarrow 2 \bullet \mathrm{OH}$

From 9 to 13 , it could be arrived at conclusions. Ozone increases photons efficiency of photocatalusis that is helpful of benzene removal. On the other hand, photocatalyst promotes ozone to separate into $\mathrm{OH}$ radical and reduces ozone output.Complete oxidation of benzene to $\mathrm{CO}_{2}$ is the final goal of the experiment, and the catalytic effect on the product distribution had been investigated. Photo-oxidation activity should be expressed as selectivity to $\mathrm{CO}_{2}$ because other byproducts except $\mathrm{CO}_{2}$ were emitted in plasma process. Here, the selectivity of $\mathrm{CO}_{2}$ was calculated as follows:
$\mathrm{CO}_{2}$ selectivity $(\%)=\frac{[\mathrm{CO}]_{2}}{6\left([\text { Benzene }]_{0}-[\text { Benzene }]\right)} \times 100$

where the $[\text { Benzene }]_{0}$ and [Benzene $]$ indicate inlet and outlet concentrations of benzene, respectively.

Though GC-MS, the main products in the plasma reactor were $\mathrm{CO}_{2}, \mathrm{H}_{2} \mathrm{O}$, and a small quantity of $\mathrm{CO}$. Ozone was the only byproduct, and no other byproducts could be detected in the tail gas. In addition, certain brownyellow products that were observed in the plasma reactor regardless of with or without catalyst appeared. The composition of the brown-yellow products was indistinct, and maybe it was aromatic polymer detected by GC-MS.

Figs. $7 \mathrm{a}$ and $7 \mathrm{~b}$ show, the removal efficiency of benzene reaches nearly $99 \%$ when benzene concentration is 600

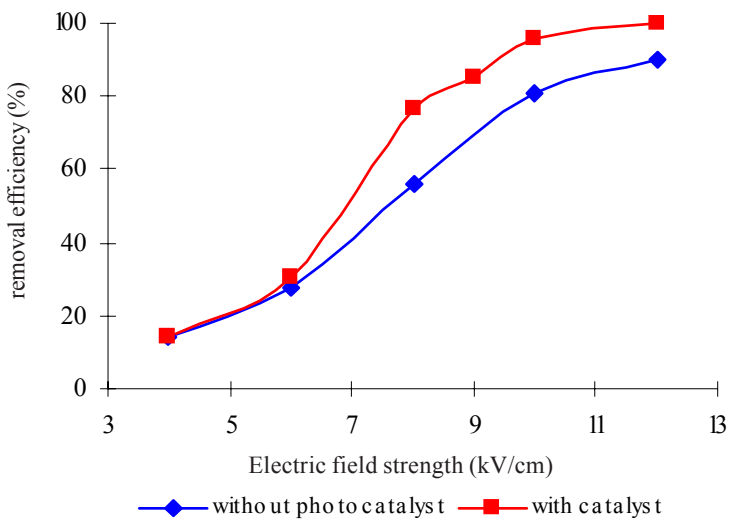

Fig. 7a: Relationship between benzene removal and electric field strength with or without catalyst when benzene concentration is $600 \mathrm{mg} / \mathrm{m}^{3}$

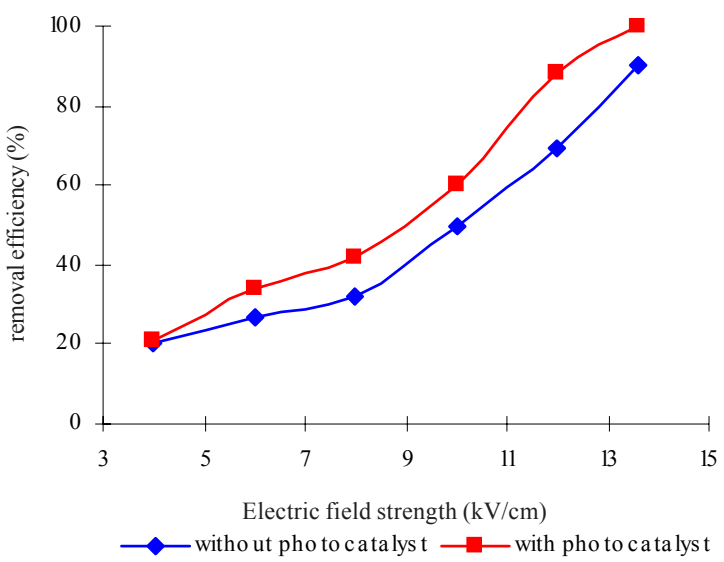

Fig. 7b: Relationship between benzene removal and electric field strength with or without catalyst when benzene concentration is $1500 \mathrm{mg} / \mathrm{m}^{3}$ 
$\mathrm{mg} / \mathrm{m}^{3}$, and the removal efficiency of benzene also reaches above $90 \%$ when benzene concentration is $1500 \mathrm{mg} / \mathrm{m}^{3}$. $\mathrm{TiO}_{2}$ can generate higher concentrations of different types of active oxygen species in non-thermal plasma, and the hybrid system has an effective utilization of active oxygen species in benzene removal based on the data presented in Fig. 7.

The minimum of $\mathrm{CO} / \mathrm{CO}_{2}$ is 0.286 and $\mathrm{CO} / \mathrm{CO}_{2}$ decreases with electrostatic field strength increasing as shown in Figs. 8a and 8b. There are no products except $\mathrm{CO}_{2}$ and $\mathrm{H}_{2} \mathrm{O}$ at $11 \mathrm{kV} / \mathrm{cm}$ and $12 \mathrm{kV} / \mathrm{cm}$. CO/CO of byproducts is lower $8.2 \%$ with catalyst than that without catalyst. These findings show the plasma reactor packed with materials with catalyst has a better selectivity of $\mathrm{CO}_{2}$ than that without catalyst.

From Fig. 8c, it is found the selectivity of $\mathrm{CO}_{2}$ ranges from $65 \%$ to $69 \%$ in the plasma reactor without catalyst, while the selectivity of $\mathrm{CO}_{2}$ ranges from $68 \%$ to $73 \%$ in the reactor with catalyst. The selectivity of $\mathrm{CO}_{2}$ is independent of electrostatic field strength. The selectivity of $\mathrm{CO}_{2}$ is enhanced due to the benzene oxidation near or on the photocatalyst surface. For that, it could be thought that intermediates and secondary products are more oxidized to $\mathrm{CO}_{2}$ on photocatalyst surface. With benzene concentration increasing, the total output of $\mathrm{CO}_{2}$ increases.

\section{CONCLUSION}

The laboratory scale plasma reactor was used for benzene removal in an air stream and the following conclusions are obtained. With ozone concentration increasing, the removal efficiency of benzene increases. Ozone concentration with packed materials is heigher than that without packed materials in the plasma reactor. Water vapor reduces ozone concentration, and occurring competitive adsorption on the surface of $\mathrm{TiO}_{2}$ Ozone concentration increases with gas flux increasing, and the removal efficiency of benzene reduces with initial concentration of benzene increasing. When both photocatalyst and ozone coexist, there will be an improved removal efficiency of benzene in the plasma reactor. Effective utilization of active oxygen species is essential in VOCs removal, and $\mathrm{TiO}_{2}$ can generate higher concentrations of different types of active oxygen species in non-thermal plasma. It is facile and promising to simultaneously hybridize plasma with $\mathrm{TiO}_{2}$ based on the data presented in this paper. Detected by GC-MS, the main

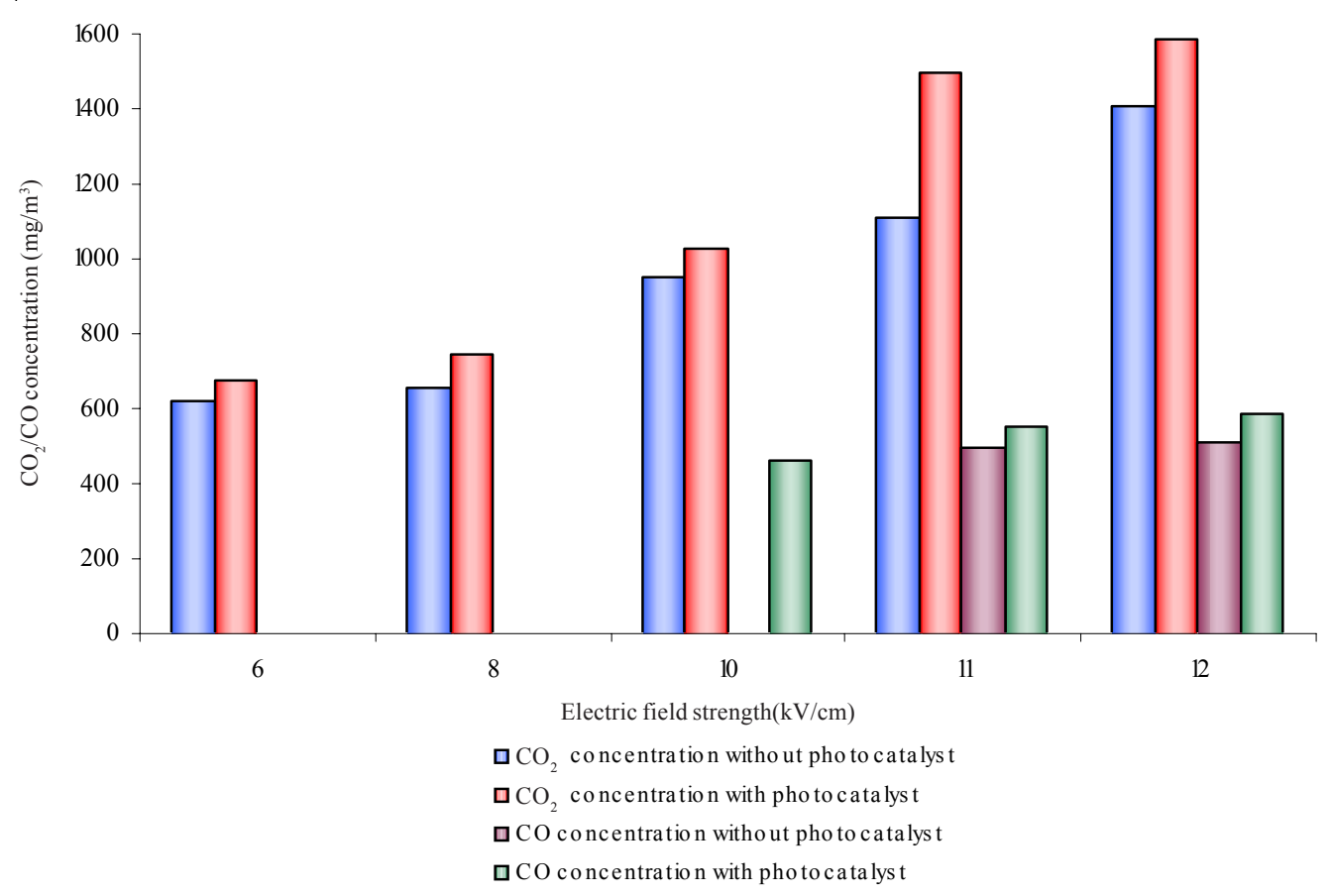

Fig. 8a: Results of byproducts detection when benzene concentration is $750 \mathrm{mg} / \mathrm{m}^{3}$ with or without catalyst 


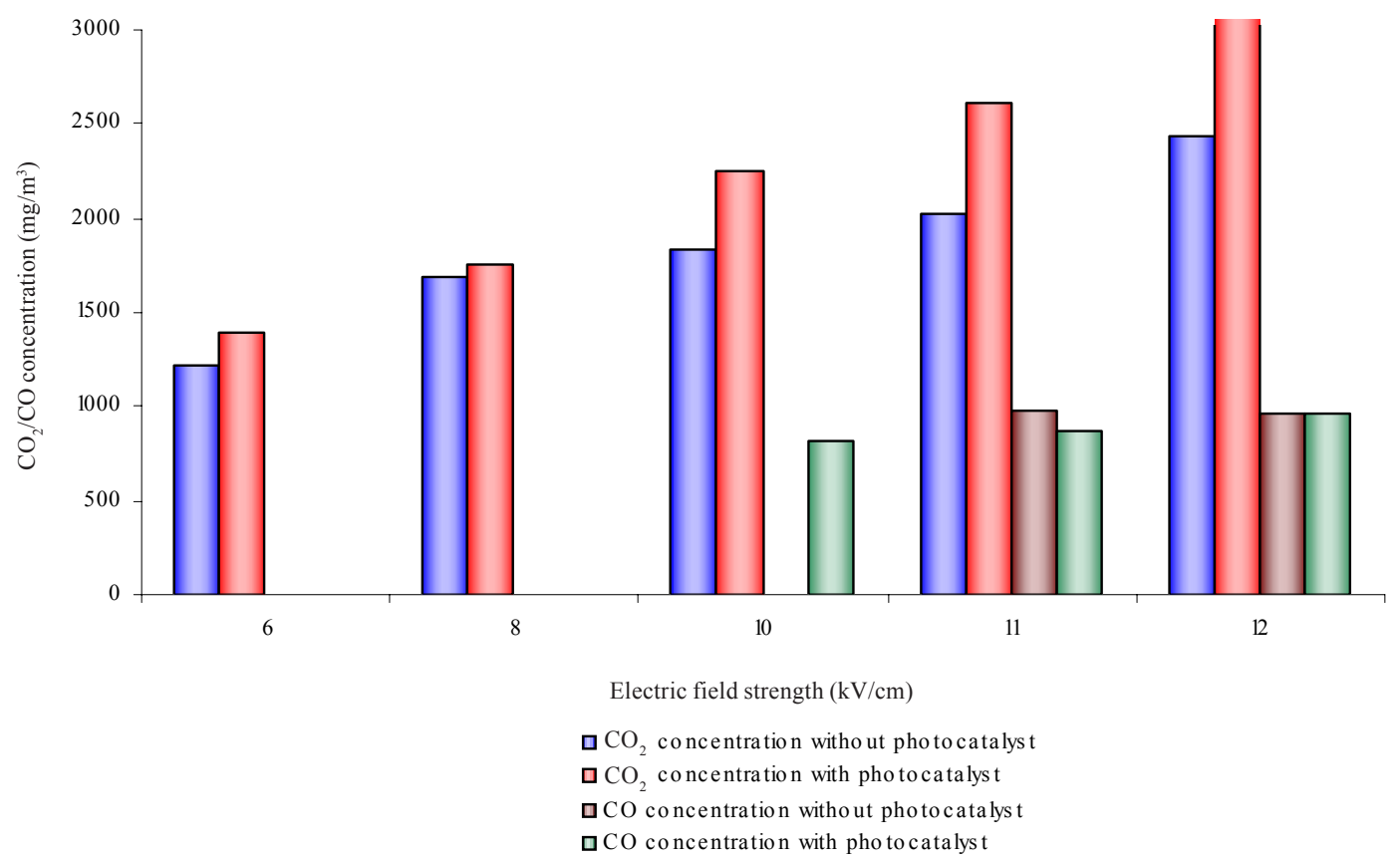

Fig. 8b: Results of byproducts detection when benzene concentration is $1500 \mathrm{mg} / \mathrm{m}^{3}$ with or without catalyst

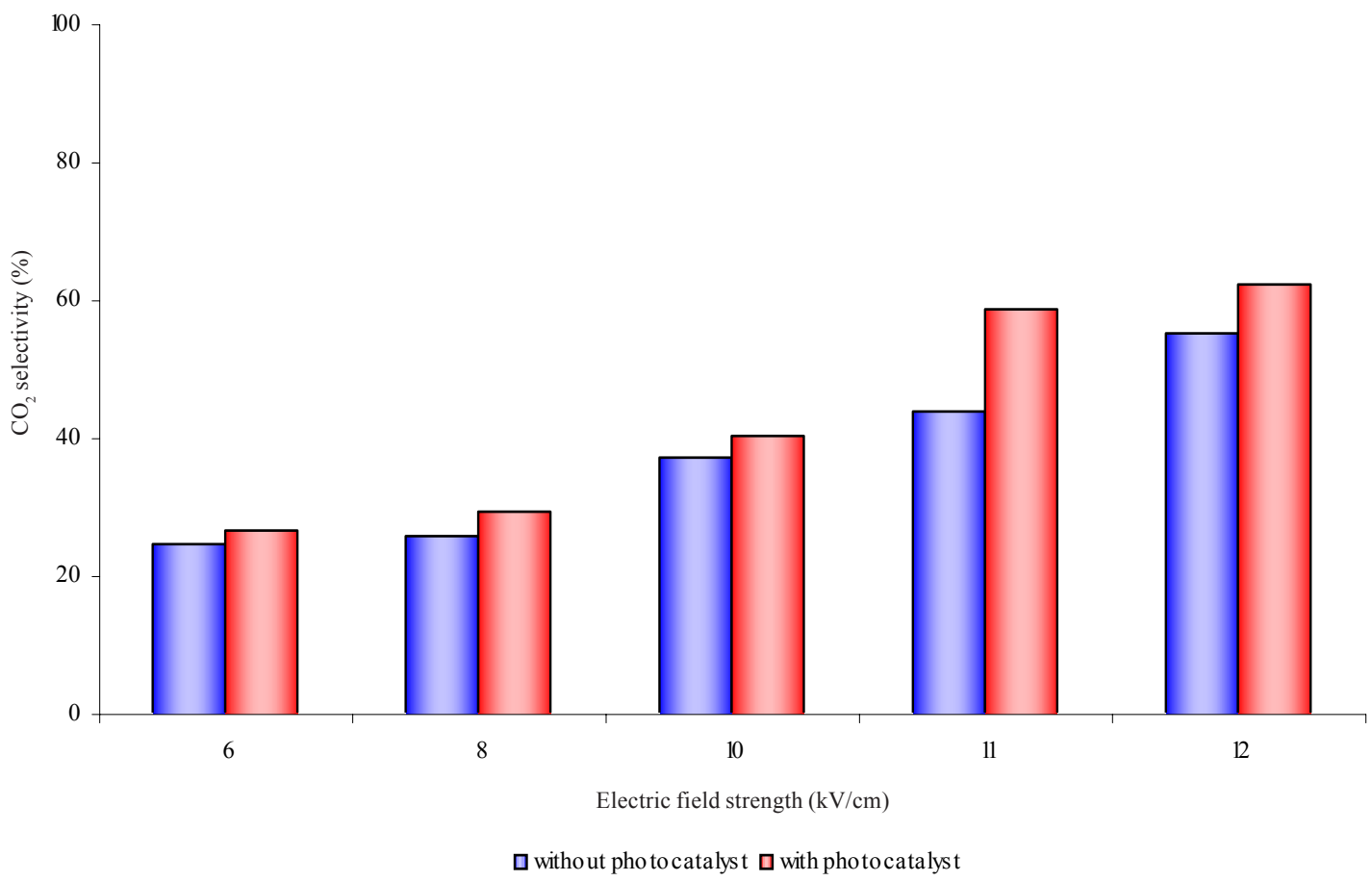

Fig. 8c: $\mathrm{CO}_{2}$ selectivity when benzene concentration is $750 \mathrm{mg} / \mathrm{m}^{3}$ with or without catalyst 
products in the plasma reactor are $\mathrm{CO}_{2}, \mathrm{H}_{2} \mathrm{O}$ and a small quantity of $\mathrm{CO}$. There are no other products detected in the tail gas. The plasma reactor packed with catalyst shows a better selectivity of $\mathrm{CO}_{2}$ than that without catalyst. The selectivity of $\mathrm{CO}_{2}$ is independent of electrostatic field strength. The selectivity of $\mathrm{CO}_{2}$ is enhanced due to the benzene oxidation near or on the photocatalyst surface. With benzene concentration increasing, the total output of $\mathrm{CO}_{2}$ increases. The hybrid system comprising a non-thermal plasma reactor and nanometer $\mathrm{TiO}_{2}$ catalyst, not only in the gas phase but on the catalyst surface, resulted in the higher energy efficiency and enhanced performance for the oxidative removal of benzene with lower medium reactivities and higher $\mathrm{CO}_{2}$ selectivity in nonthermal plasma.

\section{ACKNOWLEDGMENTS}

This work were supported by research fund for the doctoral program of Higher Education of China (No.20040005009) and funding project for Academic human resources development in Institutions of Higher Learning under the Jurisdiction of Beijing Municipality (No. 05005013 200605).

\section{REFERENCES}

Delagrange, S.; Pinard, L.; Tatiboue"t, J. M., (2007). Combination of a non-thermal plasma and a catalyst for toluene removal from air: Manganese based oxide catalysts. Appl. Catal. B: Environ., 68 (3-4), 92-98.

Durme J. V.; Dewulf, J.; Sysmans, W.; Leys, C.; Langenhove, H. V., (2007). Efficient toluene abatement in indoor air by a plasma catalytic hybrid system. Appl. Catal. B: Environ., 74 (1-2), 161-169.

Durme, J. V.; Dewulf, J.; Leys, C.; Langenhove, H. V., (2008). Combining non-thermal plasma with heterogeneous catalysis in waste gas treatment: A review. Appl. Catal. B: Environ., 78 (3-4), 324-333.

Einaga, H.; Lbusuki, T.; Futamura, S., (2001). Performance evaluation of a hybrid system comprising silent discharge plasma and manganese oxide catalysts for benzene decomposition. IEEE Trans. Ind. Appli., 37 (5), 858-863.

Futamura, S.; Einaga, H.; Kabashima, H.; Lee, Y. H., (2004). Synergistic effect of silent discharge plasma and catalysts on benzene decomposition. Catal. Today, 89 (1-2), 89-95.

Guo, Y. F.; Ye, D. Q.; Chen, K. F.; He, J. C.; Chen, W. L., (2006). Toluene decomposition using a wire-plate dielectric barrier discharge reactor with manganese oxide catalyst in situ. J. Molecular Catal. A: Chem., 245 (1-2), 93-100.

Guo, Y. F.; Ye, D. Q.; Chen, K. F.; He, J. C., (2007). Toluene removal by a DBD-type plasma combined with metal oxides catalysts supported by nickel foam. Catal. Today, 126 (34), 328-337.

Krawczyk, K.; Mlotek, M., (2001). Combined plasma-catalytic processing of nitrous oxide. Appl. Catal. B: Environ., 30 (3-4), 233-245.

Li, C.Y.; Li, M. Q., (1996). Study on Sol-Gel transition of $\mathrm{TiO}_{2}$. J. Chinese Ceramic Soc., 24 (3), 338-341.

Li, G. W.; Fan, Q. J.; Liu, Q., (1998). The control technique over the pollution caused by VOCs. J. Xi'an Univ. of Arch Tech., 30 (4), 399-402.

Li, R.; Tang, Q.; Yin, S.; Sato, T., (2006). Plasma catalysis for $\mathrm{CO}_{2}$ decomposition by using different dielectric materials. Fuel Proc. Tech., 87 (7), 617-622.

Li, W.; Han, C.; Liu, W.; Zhang, M. H.; Tao, K. Y., (2007). Expanded graphite applied in the catalytic process as a catalyst support. Catal. Today, 125 (3-4), 278-281.

Liang, Y. H.; Zhu, T.; Ma, G. D., (2006). Study on nano-TiO thin film derived by sol-gel process. J. Xi'an Univ. of Arch. Tech., 38 (6), 799-803.

Ma, G. D., (2003). Air pollution control engineering (2 $2^{\text {nd. }}$ Ed). Beijing, China Environ. Sci. Press. 105-134.

Maria, D.; Hernandez, A.; Juan, M. C.; Maira, A. J.; Soria, J.; Loddo, V.; Augugliaro, V., (2002). Ozone enhanced activity of aqueous titanium dioxide suspensions for photocatalytic oxidation of free cyanide ions. Appl. Catal. B: Environ., 39 (3), 257-267.

Magureanu, M.; Mandache, N. B.; Hu, J. C.; Richards, R.; Florea, M.; Parvulescu, V. I., (2005). Plasma-assisted catalysis for volatile organic compounds abatement. Appl. Catal. B: Environ., 61 (1-2), 12-20.

Magureanu, M.; Mandache, N. B.; Parvulescu, V. I.; Subrahmanyam, C.; Renken, A.; Kiwi-Minsker, L., (2007a). Improved performance of non-thermal plasma reactor during decomposition of trichloroethylene: Optimization of the reactor geometry and introduction of catalytic electrode. Appl. Catal. B: Environ., 74 (3-4), 270-277.

Magureanu, M.; Mandache, N. B.; Hu, J. C.; Richards, R.; Florea, M.; Parvulescu, V. I., (2007b). Plasma-assisted catalysis total oxidation of trichloroethylene over gold nano-particles embedded in SBA-15 catalysts. Appl. Catal. B: Environ.,76 (3-4), 275-281.

Muhamad, A. M.; Jiang, X. Z., (2000). Catalyst assisted destruction of trichloro ethylene and toluene in corona discharges. J. Environ. Sci., 12 (1), 7-11.

Noel, D. N., (2000). Air Pollution Control Engineering (second edition). Beijing, McGraw-Hill. 329-382.

Ogata, A.; Yamanonchi, K.; Mizuno, K., (1999). Decomposition of Benzene Using Alumina-Hybrid and Catalyst-Hybrid Plasma Reactors. IEEE Trans. Ind. Appl., 35 (6), 12891295.

Ogata, A.; Einaga, H.; Kabashima, H.; Futamura, S.; Kushiyama, S.; Kim, H. H., (2003). Effective combination of nonthermal plasma and catalysts for decomposition of benzene in air. Appl. Catal. B: Environ., 46 (1), 87-95.

Thevenet, F.; Guaitella, O.; Puzenat, E.; Herrmann, J. M.; Rousseau, A.; Guillard, C., (2007). Oxidation of acetylene by photocatalysis coupled with dielectric barrier discharge. Catal. Today, 122 (1-2), 186-194.

Urashima, K.; Chang, J., (2000). Removal of volatile organic compounds from air streams and industrial flue gases by non-thermal plasma technology. IEEE Trans. Dielectr. Electr. Insul., 7 (5), 602-614.

Wallis, A. E.; Whitehead, J. C.; Zhang, K., (2007). The removal of dichloromethane from atmospheric pressure air streams 
using plasma-assisted catalysis. Appl. Catal. B: Environ., 72 (3-4), 282-288.

Yoichi, I.; Junya, S.; Takashi, N.; Shigeyoshi, M., (2008). Synthesis of visible-light active $\mathrm{TiO}_{2}$ photocatalyst with Pt-modification: Role of $\mathrm{TiO}_{2}$ substrate for high photocatalytic activity. Appl. Catal. B: Environ., 79 (2), 117-121.

Zhang, P. Y.; Liang, F. Y.; Yu, G.; Chen, Q.; Zhu, W. P., (2003). A comparative study on decomposition of gaseous toluene by $\mathrm{O}_{3} / \mathrm{UV}, \mathrm{TiO}_{2} / \mathrm{UV}$ and $\mathrm{O}_{3} / \mathrm{TiO}_{2} / \mathrm{UV}$. J. Photochem. Photobio. A: Chem., 156 (1-3), 189-194.
Zhu, T.; Li, J.; Liang, W. J.; Dou, B. J.; Jin, Y. Q., (2007a). Gaseous phase toluene decomposition by non-thermal plasma. Environ. Pollut. Protec., 29 (12), 920-924.

Zhu, T.; Li, J.; Dou, B. J.; Liang, W. J.; Jin, Y. Q., (2007b). Study on treatment tobacco odor with non-thermal plasma technology. J. Xi'an Univ. Arch. Tech., 39 (6), 862-866.

Zhu, T.; Li, J.; Liang, W. J.; Jin, Y. Q., (2008). Research Progresses in treatment of waste gas containing volatile organic compounds by combined plasma technology. Environ. Protec. Chem. Ind., 28 (2), 121-125.

\section{AUTHOR (S) BIOSKETCHES}

Zhu, T., M. Sc, is a Ph.D. research student in air pollution control in College of Environmental and Energy Engineering, Beijing University of Technology, Beijing, China. Email: bamboozt@sohu.com

Li, J., Ph.D., Professor in environmental engineering in College of Environmental and Energy Engineering, Beijing University of Technology, Beijing, China. Email: ljian@bjut.edu.cn

Jin, Y. Q., Professor in environmental engineering in College of Environmental and Energy Engineering, Beijing University of Technology, Beijing, China.Email:jinyq@bjut.edu.cn

Liang, Y. H., Ph.D., Professor, Department of Environmental Engineering, Xi'an University of Architecture and Technology, Xi'an, China. Email:lyah@xauat.edu.cn

Ma, G. D., M. Sc, Professor, in Environmental Engineering, Department of Environmental Engineering, Xi'an University of Architecture and Technology, Xi'an, China. Email:magd@xauat.edu.cn

\footnotetext{
This article should be referenced as follows:

Zhu T.; Li, J.; Jin, Y.; Liang, Y.; Ma, G., (2008). Decomposition of benzene by non-thermal plasma processing: Photocatalyst and ozone effect. Int. J. Environ. Sci. Tech., 5 (3), 375-384.
} 